\title{
Recruitment for clinical trials: the need for public-professional co-operation
}

\author{
Raanan Gillon Imperial College Health Service and St Mary's Hospital Medical School, London University
}

'How can we achieve a partnership agreement between profession and patient so that patient care and research and development make progress?' asks Mrs Hazel Thornton, a patient who had Breast Duct Carcinoma In Situ, in her debate (1) in this issue of the journal with Professor Baum (2), one of the UK's leading surgical researchers. Not, she is quite clear, the way it's being done at present, if her own experiences are anything to go by.

Mrs Thornton expresses various concerns, including the difficulty of patients like herself receiving sufficient information to make any consent they give properly informed. However, the nub of her complaint is that at a time when she was at her most vulnerable as a patient, having just been told, after a long wait for a biopsy result following mammographic screening, that she had a form of breast cancer, she was asked to participate in a clinical trial in a way that made her feel not like a patient but like a research subject; not like one whose interests were at the front of her doctor's and nurse's mind but like one whom they wished to incorporate into scientific research designed primarily for the benefit of other possible patients in the future, rather than for her benefit as a frightened patient here and now. Instead of being offered a plan of action designed specifically for her problem she was told about the uncertainty of how best to treat Ductal Carcinoma In Situ (DCIS), given information about a clinical trial of four alternative approaches and given some written information and also a telephone number to contact if she wanted more information.

'When most in need of support I was sent away to inform myself, feeling isolated from the medical team who seemed at that moment to be a research team more interested in future generations than in my own plight ... I felt isolated, selfish, let down, illprepared for considering the options for this unknown disease of DCIS which would obviously affect my life and health. The impersonality of this trial position seemed to be attempting to deprive me of one of the most important factors of healing, contirked confidence in "my" team, whilst accentuating negative aspects of chance rather than choice' (1).
In his response (2) Professor Baum criticises current 'politically correct' requirements for informed consent in such trials. However, seeing Mrs Thornton's proposed solution as a plea for less science and less disclosure' he pleads for the alternative of 'more science and a more open and honest dialogue with our partners (the patients) in our search for better treatments for patients with cancer'. And he quotes Bertrand Russell on the vigorous splendours of the open windows of science, even if at first these 'make us shiver after the cosy indoor warmth of traditional humanising myths'. Among these myths, he says, are 'that doctor knows best and that for every patient, for every disease, there is a best treatment'.

Both papers repay careful study and raise a host of important issues, including those of informed consent and 'double standards' between research and therapy that have been addressed before in these columns (3). There is a particularly important point in Professor Baum's paper, about the need to distinguish the ethics of randomised controlled trials from the ethics of screening (2). However, one issue that Professor Baum does not address directly is what seems to be Mrs Thornton's main complaint, notably that her interests as patient here and now were subordinated - or at least were perceived by her as subordinated - to the interests of scientific research done for the benefit of others.

Now it might be that hers is an accurate perception, in which case there is little doubt that the doctors concerned were failing to fulfil the moral obligations so unequivocally expressed in the Declaration of Helsinki, whereby 'Concern for the interests of the subject must always prevail over the interests of science and society' (4).

An alternative and surely more probable interpretation is that for one reason or another Mrs Thornton was caused to mis-perceive the situation, to misinterpret it as an abandonment of the primacy of her interests when in fact her interests were being pursued in the context of offering her participation in the clinical trial. The following imaginary explanation might reflect such an interpretation.

'Mrs Thornton, we do have a treatment that would almost certainly provide a virtually 100 per 
cent cure of your DCIS even if the excision biopsy that we have already done has by some remote chance left some cancer cells behind. Thus we could remove the affected breast, and with it almost certainly even the remotest life-threatening risk of recurrence and spread of the cancer. However, this might well be excessively radical and mutilating a treatment. Unfortunately, we don't know a great deal about this condition and how it develops but suspect that even in the totally untreated state only about one in four ever become malignant. In your case we believe we have already completely removed, by the excision biopsy that you've already had, all of the cancer that we saw on your mammogram.

'If you choose not to have your breast removed you might well be taking slightly more of a risk, but we think it's a very low risk. We can offer you either a choice of currently available treatments that do not involve mastectomy, or to leave things as they are, watching out for any signs of recurrence. Alternatively, we can offer you participation in a scientific trial in which we are trying to determine the best treatment other than mastectomy, which we suspect is too radical for this condition.

'If you want to know what I personally think is the best treatment I have to tell you that while mastectomy is the most sure to prevent recurrence, it also seems to me to be excessively mutilating. However, I really don't know which of the four alternatives we are testing will turn out to be the best, taking into account recurrence rates and also sideeffects. That's why I'm involved in this trial, along with any patients who wish to participate. I will tell you what we do know from other contexts about each of the alternatives and if you have a definite preference we can simply give you that treatment. If you don't - and there's no scientific basis for a preference, though you may well have a personal basis for your particular preference - then we'd be delighted if you'd join the trial and help us discover as soon as possible which is the best treatment among these options.

'One final point - I really don't know which is the best treatment, taking into account both the benefits and the possible harms of the alternatives. If it were my wife or other loved one in your position I'd still give the same advice; unless you yourself have a definite preference it would be preferable to enter the trial.'

Of course that may well have been similar to what the surgeon did say to Mrs Thornton - we don't have the surgeon's account of what happened (for Professor Baum was not the surgeon involved in her case). But if something along those lines had occurred then it seems that both the primacy of the patient's best interests and the need for medical research would have been respected, and Mrs Thornton's misperception that she had somehow been abandoned in favour of science would have to be explained differently, perhaps in terms of a communications problem of some sort.

All that said, the fact remains that in order for nonresearching doctors to be in a position to offer their patients the best available treatment with as little harm as possible, medical research is generally necessary, both to discover what constitutes the best available treatment and to discover which treatment producing a required effect does so with least harm. Those were precisely the objectives underlying the trial to which Mrs Thornton objects. Thus medical research is prima facie a moral requirement for doctors, and stems from their Hippocratic objective of providing their patients medical benefits with minimal harm.

That is not to say, pace Professor Baum, that patients are morally obliged to participate in medical research, but it is to say that doctors should ask and encourage their patients to participate in medical research provided that such participation is not significantly against their patients' interests - and above all that it does not significantly interfere with the primary medical objective of providing the best available treatment with as little harm as possible. If sometimes this requirement leads patients to choose a treatment they personally prefer rather than to participate in a clinical trial that would yield scientifically important knowledge that seems a small price to pay for the retention of the Hippocratic moral norm of medicine.

On the other hand if patients begin to think that the imperatives of scientific research are supplanting - or even merely eroding - that vital Hippocratic moral norm of medicine, they will surely cease to trust doctors. Such an outcome can confidently be predicted to impair the ordinary practice of medicine. How much more confidently can it be predicted that any such impaired trust in doctors will undermine patients' willingness to participate as subjects in clinical trials. Thus not only morality but also scientific self-interest combine to urge the 'brave new partnership' between clinical trialists and patients advocated by Mrs Thornton. Like all partnerships it requires understanding by each partner of the interests and objectives of the other and a readiness to compromise when those interests and objectives are perceived to conflict.

\section{References}

(1) Thornton $\mathrm{H}$. Clinical trials - a brave new partnership? fournal of medical ethics 1994; 20: 19-22.

(2) Baum M. Clinical trials - a brave new partnership: a response to Mrs Thornton. Fournal of medical ethics 1994; 20: 23-25.

(3) Gillon R. Medical treatment, medical research and informed consent. Fournal of medical ethics 1989; 15: $3-5,11$

(4) Declaration of Helsinki. Widely reprinted, for example in: British Medical Association. Medical ethics today. London: BMJ Publishing Group, 1993: 330-333. 